\title{
Effects of meal and body sizes on gastric evacuation rate in brook trout Salvelinus fontinalis (Mitchill, 1814) fed commercial pellets in group feeding
}

\author{
N. S. BASCINAR, N. BASCINAR*, U. KHAN*AND K. SEYHAN* \\ Central Fisheries Research Institute, Vali Adil Yazar Cad., No. 14 Sana - 612 50, Yomra, Trabzon, Turkey \\ *Department of Fisheries Technology Engineering, Faculty of Marine Science, Karadeniz Technical University \\ Trabzon - 615 30, Turkey \\ e-mail: seldabascinar@gmail.com
}

\begin{abstract}
The effects of meal and body sizes on gastric evacuation (GE) of brook trout Salvelinus fontinalis (Mitchill, 1814) were determined following group feeding instead of feeding individually maintained fish. The GE experiments included small (ranging from 64.75 to $69.72 \mathrm{~g}$ ) and large fish (ranging from 161.59 to $170.95 \mathrm{~g}$ ). Fish in each size group was fed with three different meal sizes under similar conditions. The stomach contents were then recovered at predetermined postprandial times by serial slaughtering. The square root model adequately described the course of GE in S. fontinalis independent of meal size. The estimates of mass and length exponent obtained from $S$. fontinalis fed individually are in line with the present estimates. The result of this study would facilitate the planning and management of feeding regimes for $S$. fontinalis to minimise food waste and optimise growth.
\end{abstract}

Keywords: Fish size, Group feeding, Meal size, Salmonidae, Square root model

\section{Introduction}

Gastric evacuation (GE) experiments have been used to quantify the daily ration of fish fed either natural prey (Elliott and Persson, 1978; Bromley, 1994; Seyhan, 1994; Seyhan and Grove, 1998; Andersen, 2001) or formulated diet (Windell et al., 1972; Talbot and Higgins, 1983; Riche et al., 2004; Bascinar et al., 2016; Khan et al., 2016). GE experiments are often performed by maintaining individual fish which is considered to be a standard practice (Jobling, 1981; Persson, 1981; Bromley, 1987; Andersen, 1999; Temming and Herrmann, 2001); however, some of the fish species such as Atlantic herring Clupea harengus, Atlantic mackerel Scomber scombrus, Sprat Sprattus sprattus and sardines Sardinops sagax (Jenyns), cannot be maintained individually. Therefore, GE experiments in such species may only be performed using groups of fishes (Bernreuther et al., 2009).

GE experiments in brook trout Salvelinus fontinalis (Mitchill, 1814) based on fish fed individually have been conducted to determine the effects of body and meal sizes on GE rate (Khan et al., 2016). GE experiments in $S$. fontinalis fed in group might be interesting to compare the results with that of individually maintained experiments. In this study, small and large size groups of S. fontinalis were fed with three different ranges of meal sizes composed of commercial pellets similar to Khan et al. (2016). The main objectives of this study were to determine the effects of meal and body sizes on GE rate of S. fontinalis under group feeding.

\section{Materials and methods}

Fish and experimental conditions

Small and large sized fish of $S$. fontinalis were procured from the Surmene Faculty of Marine Sciences, Trabzon (Table 1). They were stocked in six separate holding tanks (three tanks for each size fish) which were facilitated by a recirculating water system where the oxygen saturation was ensured by means of continuous air bubbling. The fish were fed twice daily with high grade commercial pellets provided by Skretting Aquaculture (protein $44 \%$; fat $21 \%$; fibre $4 \%$; ash $9 \%$ ) for one month before conducting the experiments. The same batch of commercial pellets was used in all GE experiments.

\section{GE experiments}

All GE experiments were performed at the same time under similar environmental conditions. The experimental fish were deprived of food for $72 \mathrm{~h}$ to ensure complete emptying of the stomachs before providing the experimental diet. Groups of large and small size fish (exp. 1 and 4 in Table 1) were fed from a known amount of food to the apparent satiation. The uneaten pellets were 
retrieved from tanks using a water pipe and the mass was determined after drying in Ecocell drying oven at $60^{\circ} \mathrm{C}$ until constant weight and the same were subtracted from the initial known amount of food. The other experimental groups (exp. 2, 3 of small fish; 5, 6 of large fish) were fed with two different minimum satiation sizes of meal (Table 1). All the experimental fish were handfed.

At the end of feeding session (after $15 \mathrm{~min}$ ), four fish were carefully removed from each tank to estimate the current stomach mass $S_{t}(\mathrm{~g})$ for $t_{0}$ and afterwards the stomach contents of four fish (in most of the experiments) (Fig. 1) were recovered at predetermined postprandial times by serial slaughtering until the first empty stomach was observed. The stomach contents $\left(S_{t}\right)$ were dried to constant weight. The fish were killed by an overdose of benzocaine (150-200 $\left.\mathrm{mg} \mathrm{l}^{-1}\right)$.

\section{GE data modelling}

Linear, square root and exponential models were applied to the GE data to determine the best fit model for GE of $S$. fontinalis (He and Wurtsbaugh, 1993; Paakkonen and Marjomaki, 1997; Sweka et al., 2004).

Table 1. Basic experimental data (mean \pm S.E.) from gastric evacuation experiments in brook trout Salvelinus fontinalis fed on commercial pellets

\begin{tabular}{lllll}
\hline Exp. no. & Body mass $(\mathrm{g})$ & Total length $(\mathrm{cm})$ & Meal size $(\mathrm{g})^{*}$ & No. of observations $(\mathrm{n})$ \\
\hline 1 & $64.75 \pm 0.76$ & $18.35 \pm 0.09$ & $1.36 \pm 0.10$ & 70 \\
2 & $65.17 \pm 1.39$ & $18.47 \pm 0.12$ & $0.92 \pm 0.09$ & 49 \\
3 & $69.72 \pm 1.48$ & $19.16 \pm 0.14$ & $0.56 \pm 0.12$ & 49 \\
4 & $167.43 \pm 1.49$ & $24.35 \pm 0.19$ & $3.31 \pm 0.07$ & 65 \\
5 & $170.95 \pm 1.98$ & $24.57 \pm 0.11$ & $2.23 \pm 0.14$ & 43 \\
6 & $161.59 \pm 3.57$ & $24.38 \pm 0.15$ & $1.23 \pm 0.11$ & 44 \\
\hline
\end{tabular}

*Stomach content recovered at time 0

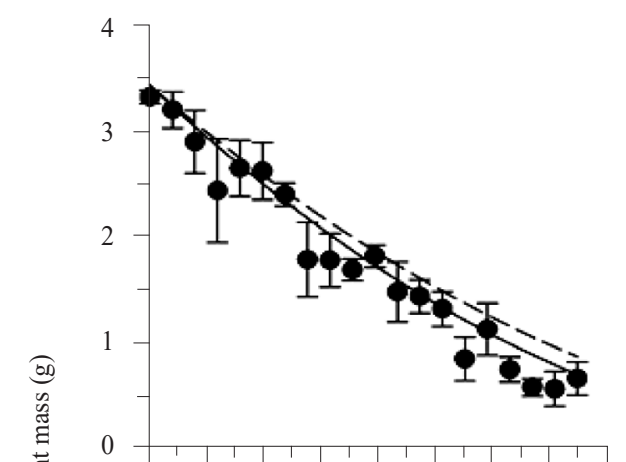

(a)

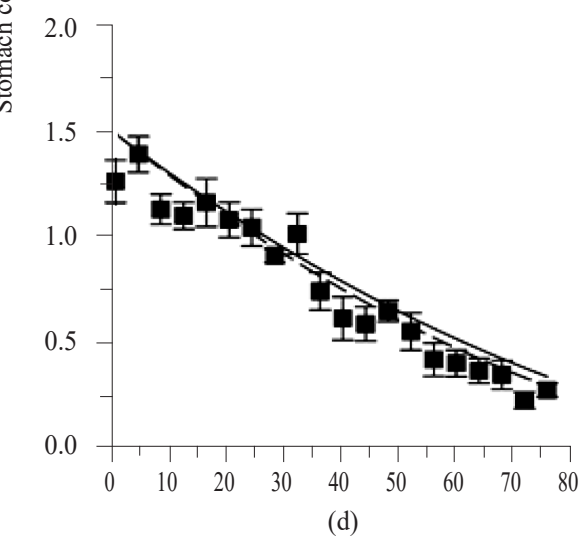

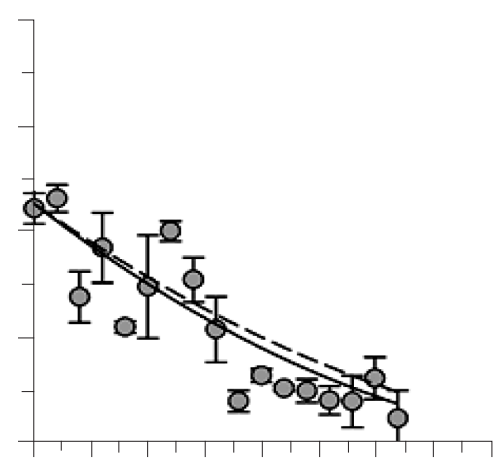

(b)

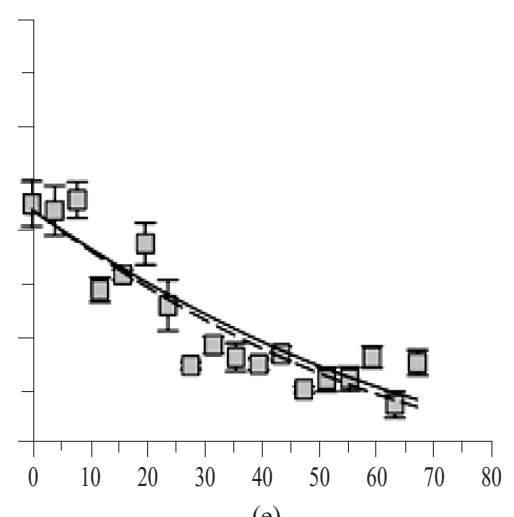

(e)

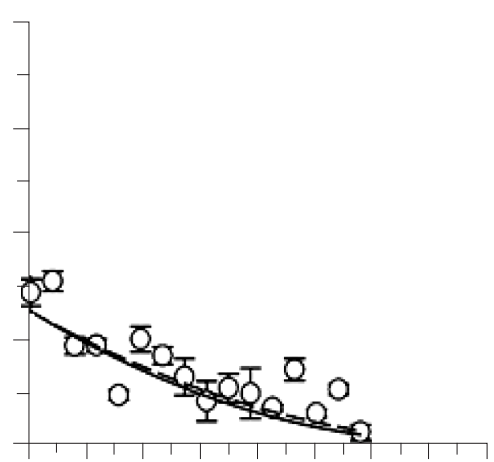

(c)

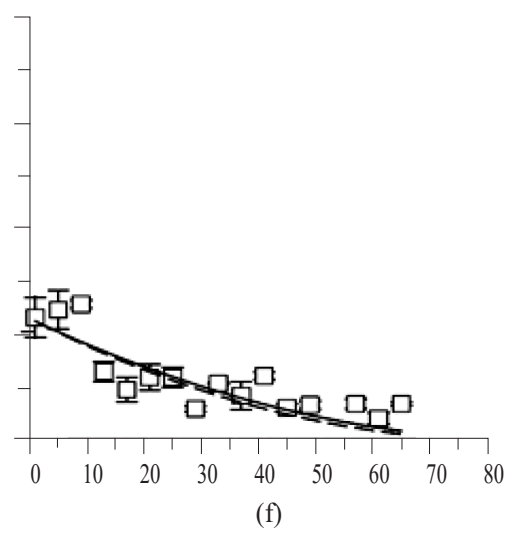

Fig. 1. Gastric evacuation of brook trout Salvelinus fontinalis fed three different meals of $3.31 \mathrm{~g}(\bullet), 2.23 \mathrm{~g}(\bullet)$ and $1.23 \mathrm{~g}(\circ)$ to large size and $1.36 \mathrm{~g}(\square), 0.92 \mathrm{~g}(\square)$ and $0.56 \mathrm{~g}(\square)$ to small size fish. The curves were provided with $\frac{\mathrm{dS}_{\mathrm{t}}}{\mathrm{dt}}=-0.0016 \mathrm{~W}^{0.553} \sqrt{\mathrm{S}_{\mathrm{t}}}(-)$ and $\frac{\mathrm{dS}_{\mathrm{t}}}{\mathrm{dt}}=-0.0004 L^{1.29} \sqrt{\mathrm{S}_{\mathrm{t}}}(---)$. Error bars indicate S.E. 
Linear model $\frac{d S_{t}}{d t}=-\rho t$ integrated: $S_{t}=a-\rho t$

Square root model $\frac{\mathrm{dS}_{\mathrm{t}}}{\mathrm{dt}}=-\rho \sqrt{\mathrm{t}}$ integrated: $\sqrt{\mathrm{S}_{\mathrm{t}}}=\sqrt{\mathrm{a}}-0.5 \mathrm{pt}$

Exponential model $\frac{d S_{t}}{d t}=-\rho t$ integrated: $S_{t}=a e^{-p x}=>\ln \left(S_{t}\right)=\ln (a)-\rho t$ (3)

where $S_{\mathrm{t}}$ is the recovered stomach content mass $(\mathrm{g}), \mathrm{t}$ is the time after ingestion of the meal $(\mathrm{h})$, the parameter a is the intersection of the regression line with Y-axis and represent some sort of the mean ingested meal size $S_{0}$ and $\mathrm{p}$ is the rate parameter $\left(\mathrm{g} \mathrm{h}^{-1}\right)$. This might be an optimal way of parameterising the evacuation rate when there is no information available about the ingested meal size of the individual fish.

\section{Model selection}

The best fit model was selected by comparing the values of the adjusted $r^{2}$ and the residual sum of squares $(R S S)$ and the one consistently providing a higher value of adjusted $r^{2}$ and the lowest value of RSS was determined as a best fit model to the data.

\section{Effects of body size}

The square root model adequately described the GE of $S$. fontinalis independently of meal size since it consistently provided a lower value of RSS and higher value of adjusted $r^{2}$. After determining the best fit model to the GE data, the effect of body size on GE rate was then analysed using simple power functions.

The rate parameter $\rho$ in equation (2) was expanded to account for the effect of fish mass $(\mathrm{g})$

$$
\sqrt{ } \mathrm{St}=\sqrt{\mathrm{a}}-0.5 \rho_{\mathrm{W}} \mathrm{W}^{\beta} \mathrm{t+ \varepsilon}
$$

where $\beta$ is the mass exponent to be estimated.

For the purpose of comparison with literature values, the length exponent was also estimated as well in the present study:

$$
\sqrt{ } \mathrm{S}_{\mathrm{t}}=\sqrt{\mathrm{a}}-0.5 \rho_{\mathrm{TL}} \mathrm{L}^{\lambda} \mathrm{t}+\varepsilon
$$

where $\lambda$ is the length exponent (total length, $\mathrm{cm}$ ) to be estimated. The parameter $\beta$ and $\lambda$ were estimated using equation (4a) and (4b) to all data combined. $\varepsilon$ is an error term.
The parameters of equation (1), (2) and (3) were estimated using PROC GLM while the parameters of the equations (4a) and (4b) were estimated using NLIN procedure (SAS, 9.04).

\section{Results}

A total of six GE experiments were performed (exp. 1-3 for small fish; exp. 4-6 for large fish (Table 1) on $S$. fontinalis by feeding a range of different meal sizes. In these experiments a total of $320 \mathrm{~S}$. fontinalis (168 small fish, 152 large fish) were used to recover stomach contents at predetermined postprandial times $t$ after ingestion of the meal. Out of these 320 fish, none of the experimental fish was found with empty stomach during the recovery of stomach contents which strongly indicates that all experimental fish were facing very low stress under experimental conditions.

\section{GE pattern and effect of meal size}

The evacuation of meal from the stomach of S. fontinalis was adequately described by square root model independent of meal size (Table 2). The difference between the adequacy of square root and linear model to describe the course of evacuation in S. fontinalis was smaller than exponential model. The exponential model poorly described the GE of $S$. fontinalis in all experiments.

\section{Effect of body size}

The effect of body size was estimated using both fish mass as well fish length separately (Table 3). The estimated mass exponent $\beta$ was 0.55 , whereas the length exponent $\lambda$ was 1.29 . The effect of body size on GE rate of S. fontinalis could be summarised by:

$$
\begin{aligned}
& \frac{\mathrm{dS}_{\mathrm{t}}}{\mathrm{dt}}=-0.0016 \mathrm{~W}^{0.553} \sqrt{\mathrm{S}_{\mathrm{t}}}\left(\mathrm{g} \mathrm{h}^{-1}\right) \\
& \frac{\mathrm{dS}_{\mathrm{t}}}{\mathrm{dt}}=-0.0004 \mathrm{TL}^{1.29} \sqrt{\mathrm{S}_{\mathrm{t}}}\left(\mathrm{g} \mathrm{h}^{-1}\right)
\end{aligned}
$$

where $\mathrm{S}_{\mathrm{t}}$ is current stomach mass $(\mathrm{g}), \mathrm{W}$ is body weight $(\mathrm{g})$, $L$ total length $(\mathrm{cm})$ and $t$ is time (h).

\begin{tabular}{|c|c|c|c|c|c|c|c|c|c|c|c|c|}
\hline \multirow{2}{*}{ Exp. no. } & \multicolumn{4}{|c|}{ Square root model } & \multicolumn{4}{|c|}{ Linear model } & \multicolumn{4}{|c|}{ Exponential model } \\
\hline & $a$ & $\rho\left(\times 10^{-2}\right)$ & $R S S$ & Adj. $r^{2}$ & $a$ & $\rho\left(\times 10^{-2}\right)$ & RSS & Adj. $r^{2}$ & $a$ & $\rho\left(\times 10^{-2}\right)$ & $R S S$ & Adj. $r^{2}$ \\
\hline 1 & $1.22 \pm 0.02$ & $-0.93 \pm 0.05$ & 0.502 & 0.857 & $1.41 \pm 0.03$ & $-1.61 \pm 0.07$ & 1.286 & 0.875 & $0.50 \pm 0.06$ & $-2.26 \pm 0.13$ & 4.237 & 0.807 \\
\hline 2 & $0.95 \pm 0.03$ & $-0.87 \pm 0.08$ & 0.574 & 0.724 & $0.91 \pm 0.05$ & $-1.28 \pm 0.12$ & 1.330 & 0.712 & $-0.08 \pm 0.09$ & $-2.51 \pm 0.24$ & 5.575 & 0.691 \\
\hline 3 & $0.74 \pm 0.03$ & $-0.71 \pm 0.08$ & 0.517 & 0.639 & $0.56 \pm 0.03$ & $-0.83 \pm 0.09$ & 0.821 & 0.605 & $-0.60 \pm 0.09$ & $-2.59 \pm 0.28$ & 6.808 & 0.643 \\
\hline 4 & $1.85 \pm 0.04$ & $-1.52 \pm 0.08$ & 1.530 & 0.838 & $3.22 \pm 0.08$ & $-3.82 \pm 0.19$ & 8.398 & 0.858 & $1.35 \pm 0.08$ & $-2.58 \pm 0.18$ & 7.396 & 0.758 \\
\hline 5 & $1.51 \pm 0.06$ & $-1.73 \pm 0.16$ & 1.620 & 0.721 & $2.21 \pm 0.12$ & $-3.47 \pm 0.31$ & 6.892 & 0.742 & $0.90 \pm 0.13$ & $-3.39 \pm 0.37$ & 8.944 & 0.666 \\
\hline 6 & $1.04 \pm 0.05$ & $-1.06 \pm 0.15$ & 1.319 & 0.551 & $1.08 \pm 0.08$ & $-1.64 \pm 0.22$ & 3.159 & 0.551 & $0.14 \pm 0.16$ & $-3.15 \pm 0.49$ & 15.337 & 0.482 \\
\hline
\end{tabular}

Table 2. Estimates ( \pm S.E.) of the intercept $a$ and rate parameter $\rho$ in the square root model: $\sqrt{S_{t}}=\sqrt{ }$ a- $0.5 \rho t$, linear model: $S_{t}=a-\rho t$ and exponential model: $\ln \left(\mathrm{S}_{\mathrm{t}}\right)=\ln (\mathrm{a})$ - $\rho$ t from gastric evacuation data of brook trout Salvelinus fontinalis fed meals of commercial pellets 
Table 3. Summary statistics for parameter estimation of the expanded empirical model of gastric evacuation equations (3a) $\sqrt{ } \mathrm{S}_{\mathrm{t}}=\sqrt{\mathrm{a}}-0.5 \rho_{\mathrm{w}} \mathrm{W}^{\beta} \mathrm{t}+\varepsilon$ and equation (3b) $\sqrt{ } S_{t}=\sqrt{a}-0.5 \rho_{L} L^{\lambda} t+\varepsilon$ for combined data on gastric evacuation of meals of commercial pellets fed to brook trout Salvelinus fontinalis

\begin{tabular}{llllll}
\hline \multirow{2}{*}{ Parameter } & \multirow{2}{*}{ Estimate } & \multicolumn{2}{c}{$95 \% \mathrm{CL}$} & & \\
\cline { 3 - 4 } & & Lower & Upper & Adj. $r^{2}$ & Obs. (n) \\
\hline$\rho_{\mathrm{W}}$ & 0.0016 & 0.0004 & 0.0019 & 0.722 & 321 \\
$\mathrm{~B}$ & 0.553 & 0.3485 & 0.6337 & & 321 \\
$\rho_{\mathrm{TL}}$ & 0.0004 & 0.0003 & 0.0009 & 0.301 & 321 \\
$\lambda$ & 1.2901 & 0.9217 & 1.4340 & & 321 \\
\hline
\end{tabular}

\section{Discussion}

\section{GE pattern in $S$. fontinalis}

The square root model adequately described the course of evacuation in $S$. fontinalis which is in accordance with the previously published data (Bascinar et al., 2016; Khan et al., 2016). Moreover, the course of meal evacuation in $S$. fontinalis fry has also been found to be best described by square root model (Seyhan, K., unpublished data). Sweka et al. (2004) examined the effect of temperature on GE rate of $S$. fontinalis at five temperatures (i.e. 4.3, 9.1, 12.1, 15.6 and $17.0^{\circ} \mathrm{C}$ ) and observed that square root model could adequately describe the GE of $S$. fontinalis at 12.1 and $17.0^{\circ} \mathrm{C}$ whereas at other temperatures (4.3, 9.1 and 15.6), linear model was found to best fit to the GE data. They fed the fish on a mixed diet of larval fly Sarcophaga bullata and larval beetle Zophobus morio with a standard meal size. The nature of diet has been found to affect the shape of evacuation (Bromley, 1994) and the deviation from the square root model in the study by Sweka et al. (2004) for individual meals may reflect prey heterogeneity (robust exoskeleton of the prey i.e., insect). According to Khan et al. (2016) such deviation from the square root function could be removed using combined data on different meal sizes such as in Andersen (2001) where the square root model adequately describes the GE of shrimp (type of prey) independently of meal size; though for individual meals, the curve is more linear. The general applicability of the square root model properly describes the evacuation of different fish and crustacean prey from the stomachs of whiting Merlangius merlangus, saithe Pollachius virens and cod Gadus morhua, fed different meal sizes (Andersen, 2001). The square root model has been used to describe the pattern of evacuation in various other fish species such as pikeperch Stizostedion lucioperca (Koed, 2001) and coho salmon Oncorhynchus kisutch (Andersen and Beyer, 2007); different gadoids (Jones, 1974; Temming and Herrmann, 2003) and turbot Scophthalmus maximus (Grove et al., 1985).

\section{Effect of meal size}

The estimated rate parameters obtained from different meal sizes for large and small size groups of $S$. fontinalis do not seem to differ greatly within exp. 1-3 and 4-6 which suggests that the square root model independently of meal size described the course of evacuation of $S$. fontinalis (Fig. 1). In contrast to individual fish experiment, group feeding data have some variation that could result in such minor variation in rate parameters (Table 2). Khan et al. (2016) tested the effect of meal sizes in small and large size $S$. fontinalis following individual fish experiments and reported square root to describe the course of GE independent of meal size.

\section{Effect of body size}

The estimated value of length and mass exponents were within the range of previously reported values $[(\beta=0.40 \pm 0.05 ; \lambda=1.31 \pm 0.17( \pm 95 \%$ C.I. $)]$ by Khan et al. (2016) for $S$. fontinalis. The estimated length exponent also lies within the range of 1.3-1.4 obtained for different gadoids including Atlantic cod (Jones, 1974; dos Santos and Jobling 1992; Andersen, 2001, 2012). Also, the mass exponent reported by these authors was in line with the present one on $S$. fontinalis just like the length exponent. However, some studies have reported a lower value of the length exponent for pike perch (Koed, 2001) and Atlantic cod (dos Santos and Jobling, 1995; Temming and Herrmann, 2003). The lower length exponent was due to the fact that the larger fish were fed with larger size prey containing higher energy (Pedersen and Hislop, 2001). Diet with higher energy has been found to depress the GE rate of fish (Jobling, 1987). Similar to length exponent, a lower value of mass exponent was also reported by Grove et al. (1985) for turbot fed pellet feed.

The present study should add a confidence to the belief that the results obtained from individually maintained fish could be applied to group study and vice versa. Using simple regression to converted data (for square root and exponential model) might give adequate results for the GE data where the initial meal ingested by each fish is unknown.

\section{Acknowledgements}

The authors gratefully acknowledge funding from the Scientific and Technological Research Council of Turkey (TUBIITAK) (Grant no: 1130362).

\section{References}

Andersen, N. G. 1999. The effects of predator size, temperature and prey characteristics on gastric evacuation in whiting. J. Fish Biol., 54(2): 287-301. 
Andersen, N. G. 2001. A gastric evacuation model for three predatory gadoids and implications of using pooled field data of stomach contents to estimate food rations. J. Fish Biol., 59(5): 1198-1217.

Andersen, N. G. 2012. Influences of potential predictor variables on gastric evacuation in Atlantic cod Gadus morhua feeding on fish prey: parameterisation of a generic model. J. Fish Biol., 80(3): 595-612.

Andersen, N. G. and Beyer, J. 2007. How are prey fishes of multiple meals evacuated from the stomach of a piscivorous fish? J. Fish Biol., 71(1): 219-234.

Bascinar, N., Bascinar, S. N., Seyhan, K. and Khan, U. 2016. The effect of temperature on the rate of gastric evacuation in brook trout Salvelinus fontinalis fed on commercial pellets: group-feeding. Pakistan J. Zool., 48(6): 1899-1904.

Bernreuther, M., Temming, A. and Herrmann, J. P. 2009. Effect of temperature on the gastric evacuation in sprat Sprattus sprattus. J. Fish Biol., 75(7): 1525-1541.

Bromley, P. 1987. The effects of food type, meal size and body weight on digestion and gastric evacuation in turbot, Scophthalmus maximus L. J. Fish Biol., 30(4): 501-512.

Bromley, P. J. 1994. The role of gastric evacuation experiments in quantifying the feeding rates of predatory fish. Rev. Fish Biol. Fish., 4(1): 36-66.

dos Santos, J. and Jobling, M. 1992. A model to describe gastric evacuation in cod (Gadus morhua L.) fed natural prey. ICES J. Mar. Sci.: Journal du Conseil, 49(2):145-154.

dos Santos, J. and Jobling, M. 1995. Test of a food consumption model for the Atlantic cod. ICES J. Mar. Sci.: Journal du Conseil, 52(2): 209-219.

Elliott, J. and Persson, L. 1978. The estimation of daily rates of food consumption for fish. J. Anim. Ecol., 47: 977-991.

Grove, D., Moctezuma, M., Flett, H., Foott, J., Watson, T. and Flowerdew, M. 1985. Gastric emptying and the return of appetite in juvenile turbot, Scophthalmus maximus L., fed on artificial diets. J. Fish Biol., 26(3): 339-354.

He, E. and Wurtsbaugh, W. A. 1993. An empirical model of gastric evacuation rates for fish and an analysis of digestion in piscivorous brown trout. Trans. Am. Fish. Soc., 122(5): 717-730.

Jobling, M. 1981. Dietary digestibility and the influence of food components on gastric evacuation in plaice, Pleuronectes platessa L. J. Fish Biol., 19(1): 29-36.

Jobling, M. 1987. Influences of food particle size and dietary energy content on patterns of gastric evacuation in fish: test of a physiological model of gastric emptying. J. Fish Biol., 30(3): 299-314

Jones, R. 1974. The rate of elimination of food from the stomachs of haddock Melanogrammus aeglefinus, cod Gadus morhua and whiting Merlangius merlangus. Journal de Conseil International pour l'Exploration de la Mer, 35(3): 225-243.
Khan, U., Seyhan, K., Bascinar, N. and Bascinar, N. S. 2016 Satiation meal and the effects of meal and body sizes on gastric evacuation rate in brook trout Salvelinus fontinalis fed commercial pellets. J. Fish Biol., 89(2): 1227-1238.

Koed, A. 2001. The effects of meal size, body size and temperature on gastric evacuation in pikeperch. J. Fish Biol., 58(1): 281-290.

Paakkonen, J. P. and Marjomaki, T. 1997. Gastric evacuation rate of turbot fed single-fish meals at different temperatures. J. Fish Biol., 50(3): 555-563.

Pedersen, J. and Hislop, J. 2001. Seasonal variations in the energy density of fishes in the North Sea. J. Fish Biol., 59(2): 380-389.

Persson, L. 1981. The effects of temperature and meal size on the rate of gastric evacuation in perch (Perca fluviatilis) fed on fish larvae. Freshwat. Biol., 11(2): 131-138.

Riche, M., Haley, D., Oetker, M., Garbrecht, S. and Garling, D. 2004. Effect of feeding frequency on gastric evacuation and the return of appetite in tilapia Oreochromis niloticus (L.). Aquaculture, 234(1): 657-673.

Seyhan, K. 1994. Gastric emptying, food consumption and ecological impact of whiting, Merlangius merlangus (L.) in the Eastern Irish Sea Marine Ecosystem, Doctoral dissertation, University College of North Wales, United Kingdom.

Seyhan, K. and Grove, D. 1998. Food consumption of whiting, Merlangius merlangus, in the Eastern Irish Sea. Fish. Res., 38(3): 233-245.

Sweka, J. A., Keith Cox, M. and Hartman, K. J. 2004. Gastric evacuation rates of brooktrout. Trans. Am. Fish. Soc., 133(1): 204-210.

Talbot, C. and Higgins, P. 1983. A radiographic method for feeding studies on fish using metallic iron powder as a marker. J. Fish Biol., 23(2): 211-220.

Temming, A. and Herrmann, J. P. 2003. Gastric evacuation in cod: prey-specific evacuation rates for use in North Sea, Baltic Sea and Barents Sea multi-species models. Fish. Res., 63(1): 21-41.

Temming, A. and Herrmann, J. P. 2001. Gastric evacuation in horse mackerel. I. The effects of meal size, temperature and predator weight. J. Fish Biol., 58(5): 1230-1245.

Windell, J., Hubbard, J. and Horak, D. 1972. Rate of gastric evacuation in rainbow trout fed three pelleted diets. Progr Fish Cultur, 34(3): 156-159.

Date of Receipt $\quad$ : 16.06 .2016

Date of Acceptance ： 12.06.2017 